\title{
Stereotactic biopsy for intracranial space occupying lesions: Experience in a referral hospital in Mexico
}

\section{Biopsia por estereotaxia para lesiones intracraneales: experiencia de un hospital de referencia en México}

\author{
José L. Navarro-Olvera*, Gustavo Parra-Romero', José D. Carrillo-Ruiz'1,2,3, Gustavo Aguado-Carrillo', \\ Julián E. Soto-Abraham ${ }^{1}$, and Aldo F. Hernández-Valencia ${ }^{1}$ \\ ${ }^{1}$ Stereotactic and Radiosurgery Department, Functional Neurosurgery, Mexico General Hospital, Mexico City; ${ }^{2}$ Research Direction, Mexico General \\ Hospital, Mexico City; ${ }^{3}$ Faculty of Health Sciences, Anahuac University North Campus, Mexico City, Mexico
}

\begin{abstract}
Background: Stereotactic brain biopsy (SBB) is used for establishing the histological diagnosis of intracranial lesions that are not amenable for a direct surgical approach. Objective: The objective of the study was to describe our experience having an evaluation of the biopsy sample by a neuropathologist during SBB. Materials and methods: Retrospective analysis of 140 consecutive patients who underwent SBB between 2014 and 2018 in whom trans-operatory analysis of the sample was performed. Results: There were 56\% men. The mean age was 45 years. Histological diagnosis was performed in 131 of 140 patients (94\% overall diagnostic yield). The presurgical radiological diagnosis was correct in $39 \%$. Neoplastic lesions were reported in 108 cases, and 32 were non-neoplastic. We performed craniotomy and resection after biopsy in 14\%. We found complications in $6 \%$ of patients. Conclusions: SBB continues to be a safe, useful, and inexpensive procedure. The diagnostic performance of SBB increases when intraoperative cytological evaluation by a neuropathologist is included in the study.
\end{abstract}

Key words: Biopsy. Brain tumor. Diagnostic yield. Histopathology. Stereotaxy.

\section{Resumen}

Antecedentes: la biopsia cerebral por estereotaxia (SBB) se utiliza para establecer el diagnóstico histológico de lesiones intracraneales que no son susceptibles de un abordaje quirúrgico directo. Objetivo: describir nuestra experiencia de tener una evaluación de la muestra de biopsia por un neuropatólogo durante el procedimiento. Material y métodos: análisis retrospectivo de 140 pacientes consecutivos sometidos a SBB entre 2014-2018 en los que se realizó análisis transoperatorio de la muestra. Resultados: El 56\% fueron hombres. La edad promedio fue de 45 años. El diagnóstico histológico se realizó en 131 de 140 pacientes (rendimiento diagnóstico global del 94\%). El diagnóstico radiológico prequirúrgico fue correcto solo en el $39 \%$. Se identificaron lesiones neoplásicas en 108 casos, y en 32 se documentaron lesiones no neoplásicas. En el 14\% de los casos se realizó posterior a la biospia craneotomía y resección de la lesión. Encontramos complicaciones en el $6 \%$ de los pacientes. Conclusiones: SBB sigue siendo un procedimiento seguro, útil y económico. El rendimiento diagnóstico de SBB aumenta cuando se incluye la evaluación citológica intraoperatoria por un neuropatólogo.

Palabras clave: Biopsia. Estereotaxia. Histopatología. Rendimiento diagnóstico. Tumor cerebral.

\section{Correspondence:}

*José L. Navarro-Olvera

Dr. Balmis, 148

Cuauhtémoc

Date of reception: 15-09-2020

C.P. 06720, Ciudad de México, México Date of acceptance: 09-12-2020

E-mail: luiginavarro97@ @otmail.com

DOI: 10.24875/CIRU.20001009

Cir Cir. 2021;89(6):763-768

Contents available at PubMed www.cirugiaycirujanos.com
of the CC BY-NC-ND license s of the CC BY-NC-ND license (http://creativecommons.org/licenses/by-nc-nd/4.0/). 


\section{Introduction}

Stereotactic brain biopsy (SBB) is used for establishing the histological diagnosis of intracranial lesions that, in view of their location or imaging characteristics, are not amenable for a direct surgical approach 1 .

Frame-based system has generally been considered the gold standard method for obtaining $\mathrm{SBB}^{2}$ over the frameless technique, although without significant differences in the diagnostic success between the two techniques, which are estimated in different reports to be between 89 and $94 \%^{2-5}$. Since SBB, although considered minimally invasive, is a surgical procedure carrying on some risks, it is important to optimize its success in providing a conclusive diagno$\mathrm{sis}^{6-8}$. In the present report we evaluated the diagnostic success of a frame based system SBB, having an intra-operative evaluation by a neuropathologist of the adequacy of multi-sample material obtained for histopathological analysis, against the complication rate of the procedure.

\section{Materials and methods}

We performed a retrospective analysis of 140 consecutive cases with intracranial lesions demonstrated by enhanced Magnetic Resonance Imaging (MRI) and operated over a period of 53 months (February 2014June 2018). Patients considered for SBB were those in whom the location of lesions or their possible etiology precluded an open surgical intervention. Therefore, the aim of SBB was to establish the histological diagnosis of lesions for defining the most appropriate therapeutic approach in each patient.

The procedures were performed at the Unit for Stereotactic and Functional Neurosurgery of Mexico General Hospital.

One hundred and eight cases corresponded to suspected neoplastic lesions. Twenty (14\%) of them benefited by subsequent ressective or tumor reduction surgical procedures. Others underwent chemotherapy and/or radiotherapy based on the histopathological diagnosis. Eighty-four (60\%) were lesions located in eloquent areas, and thirty-six (24\%) lesions in patients with comorbidities, functional impairment, or advanced age that increased risk for a major surgical procedure. Lesions were intracerebral subcortical, deeply located in the frontal $26 \%$, temporal $10 \%$, parietal $9 \%$, and occipital $2 \%$ lobes, thalamus $19 \%$,
Table 1. Anatomic location of brain lesions

\begin{tabular}{lcc}
\hline Location & $\mathbf{n}$ & $\%$ \\
\hline Frontal & 36 & 26 \\
Thalamus & 27 & 19 \\
Temporal & 14 & 10 \\
Parietal & 12 & 9 \\
Corpus Callosum & 10 & 7 \\
Basal Ganglia & 10 & 7 \\
Brainstem & 7 & 5 \\
Paraventricular & 6 & 4 \\
Pineal region & 5 & 4 \\
Occipital & 3 & 2 \\
Sellar region & 1 & 1 \\
Multifocal & 9 & 6 \\
Total & 140 & 100 \\
\hline
\end{tabular}

corpus callosum $7 \%$, periventricular $4 \%$, pineal region $4 \%$, basal ganglia $7 \%$, infratentorial $5 \%$, and $6 \%$ were diffuse or multifocal (Table 1). Thirteen (9\%) were cases associated to human immunodeficiency virus (HIV).

All cases had a contrasted MRI. Axial T1 Weighted images sequence $1.0 \mathrm{~mm}$ thick was used for planning the stereotactic approach. Patients signed an informed consent approved by the Institutional Ethics Committee Board that complies with Helsinki declaration. Demographic data, clinical and radiographic characteristics are presented as measures of central tendency. Analyses of differences between categorical variables were performed with the Chi-square test. $p<0.05$ was considered statistically significant.

Under local anesthesia the Zamorano-Dujovny (ZD) stereotactic frame (FL Fischer, Freiburg, Germany) was placed aligned to the orbitomeatal plane. An enhanced cerebral computed tomography (CT) was obtained under stereotactic condition with $2 \mathrm{~mm}$ thick slices without interval. Stereotactic surgical planning used the PRAEZIS ${ }^{\circledR}$ software (Praecis AG, Heidelberg, Germany) of fused MRI and the enhanced CT for defining trajectories avoiding vascular structures. The targets for taking samples also avoided areas with restricted diffusion in the MRI sequences, considering those areas with great proportion of necrotic tissue and therefore with poor diagnostic value. 
For biopsies in the pineal region trajectories were carefully planned avoiding the ventricular system and vascular structures, verifying the trajectory in the CTMRI multiplanar images of the software. Precoronal entry point was preferred for lesions located nearby frontal, temporal, basal ganglia, and hypothalamus. Postcoronal entry point was used for lesions in the upper brainstem, periventricular, and corpus callosum. The parietal entry point was used for parietal and occipital lesions, and the sub-occipital entry point with inverted frame positioning was used for cerebellar lesions. At least, two targets were planed per patient and defined in the $\mathrm{x}, \mathrm{y}$, and $\mathrm{z}$ planes.

Procedures were performed under local anesthesia and mild sedation in most instances. The pre-established coordinates were verified in the stereotactic frame prior starting the procedure. Burr hole performed with a $14 \mathrm{~mm}$ auto-stop drill centered at the stereotactic cranial entry point. Dural opening performed by burning the dura using the monopolar cautery applied to the tip of the biopsy needle, avoiding cerebrospinal fluid drainage that might create a brain shift. Aspiration through a biopsy needle with a $2.5 \mathrm{~mm}$ lateral window at the side of the needle tip was obtained. Typically, sampling included the four quadrants of the needle obtaining $2.3 \mathrm{~mm}$ samples. Thereafter, biopsy needle was advanced $2.5 \mathrm{~mm}$ below the first sampled site and sampling was repeated in the same manner, obtaining a total of 8 samples. Neuropathologist in the operating room received and labeled the biopsied samples, staining them with Hematoxylin-Eosin. After an immediate microscopic examination, he evaluated if sampling was satisfactory for diagnosis. In those cases where the tissue obtained was not sufficient for the neuropathologist, the biopsy needle was directed to the $2^{\text {nd }}$ target and the neuropathologist evaluated the biopsy material in the same way. One the biopsy was declared satisfactory for diagnosis; all samples were immersed in a paraffin block and taken to the neuropathology department for specific staining and immunohistochemistry, according to the type of lesion and the needs for its identification.

To rule out subclinical complications and to corroborate the adequate biopsied site, CT was performed within $24 \mathrm{~h}$ after the surgical procedure in all cases and fused with the pre-operative studies.

\section{Results}

Among the 140 SBB from February 2014 to June 2018, there were $79(56 \%)$ men and 61 (44\%) women.
The mean age was 45 years (standard deviation [SD] 15.9 years). Histological diagnosis was performed in 131 of the 140 cases ( $94 \%$ overall diagnostic yield). The presurgical radiological diagnosis was correct in $39 \%$ of the cases. The mean hospital stay was 1.5 days. Of the 140 biopsied cases, $108(77 \%)$ corresponded to neoplastic lesions and $32(23 \%)$ were non-neoplastic. We performed craniotomy and resection after biopsy in $14 \%$ of cases $(n=20)$.

Regarding neoplastic lesions, high-grade astrocytomas (Glioblastoma WHO G IV and anaplastic astrocytoma WHO GIII) were the most frequently diagnosed group $40 \%(n=56)$, we found an increase in the mean age of these patients ( $50.4 \pm 15.6$ years) compared to the rest of the sample. The radiological diagnosis was correct in $34 \%$. Subsequent craniotomy and resection was performed in only six cases $(9 \%)$.

The second group in frequency corresponded to low-grade astrocytomas (WHO GI and GII), we found 19 cases (14\%), with a correct radiological diagnosis in $48 \%$ and a subsequent need for complete resection in $32 \%(n=6)$. We documented ten metastasis $(7 \%)$, primary tumors were identified in $90 \%$ of cases (six lung, two melanoma, and one thyroid), the radiological diagnosis was correct only in $20 \%$ of the patients and only one required complementary surgical management (Table 2).

Regarding non-neoplastic, toxoplasmosis was the most frequent lesion $4 \%(n=6)$, followed by tubercuIoma, abscesses, HIV encephalitis, demyelinating processes, and venous angioma ( $1 \%$ each). The radiological diagnosis was correct in $47 \%$ of infections and $100 \%$ of vascular etiologies (Fig. 1).

In $9(6 \%)$ cases, the diagnosis could not be determined by the SBB. In these patients, the mean age was $40.22 \pm 12.2$ years, there were 8 men $(89 \%)$. Radiological diagnosis corresponded to: 3 high-grade astrocytomas, 2 tuberculomas, 2 lymphomas, and 2 metastases. With respect to the location, we found 5 frontal, 2 brainstem, 1 thalamus, and 1 basal ganglia lesion (Table 2).

In 20 patients (14\%), a complementary resection was performed after a certain diagnosis obtained by SBB. Of these, $10 \%$ of glioblastomas $(n=4), 100 \%$ of pilocytic astrocytomas ( $n=4), 33 \%$ of diffuse astrocytomas $(n=2), 33 \%$ of anaplastic astrocytomas $(n=2), 100 \%$ of meningiomas $(n=2), 100 \%$ of arteriovenous malformations ( $n=1), 50 \%$ of venous angiomas ( $n=1), 50 \%$ of central neurocytomas $(n=1)$, $50 \%$ of gangliogliomas $(n=1), 12.5 \%$ of lymphomas $(n=1)$, and $10 \%$ of metastases $(n=1)$. 
Table 2. Histopathology of Stereotactic brain biopsies

\begin{tabular}{|c|c|c|}
\hline Neoplastic Lesions 108 (77\%) & n (\%) & $\begin{array}{c}\text { MRI \% } \\
\text { accuracy }\end{array}$ \\
\hline Glioblastoma & $41(29)$ & 34 \\
\hline Anaplastic astrocytoma & $15(11)$ & 33 \\
\hline Low grade astrocytoma & $9(6)$ & 44 \\
\hline Lymphoma & $8(6)$ & 50 \\
\hline Diffuse astrocytoma & $6(4)$ & 50 \\
\hline Pilocytic astrocytoma & $4(3)$ & 50 \\
\hline Germ cell tumors & $5(4)$ & 40 \\
\hline Ganglioglioma & $2(1)$ & 0 \\
\hline Meningioma & $2(1)$ & 50 \\
\hline Central neurocytoma & $2(1)$ & 100 \\
\hline Anaplastic oligodendroglioma & $1(1)$ & 0 \\
\hline Primitive neuroectodermal tumors & $1(1)$ & 0 \\
\hline Pineocytoma & $1(1)$ & 0 \\
\hline Gliomatosis cerebri & $1(1)$ & 0 \\
\hline Metastasis & $10(7)$ & 20 \\
\hline Non neoplastic lesions $32(22.9 \%)$ & n (\%) & \\
\hline Toxoplasmosis & $6(4)$ & 66 \\
\hline Tuberculoma & $2(1)$ & 100 \\
\hline Abscess & $2(1)$ & 100 \\
\hline HIV encephalitis & $2(1)$ & 0 \\
\hline Demyelinating process & $2(1)$ & 0 \\
\hline Venous angioma & $2(1)$ & 100 \\
\hline Syphilitic Gumma & $1(1)$ & 0 \\
\hline Neurocysticercosis & $1(1)$ & 0 \\
\hline Cerebral amebiasis & $1(1)$ & 0 \\
\hline Progressive multifocal leukoencephalopathy & $1(1)$ & 0 \\
\hline Vasculitis & $1(1)$ & 100 \\
\hline AVM & $1(1)$ & 100 \\
\hline Actinomyces spp & $1(1)$ & 0 \\
\hline Non diagnostic & $9(6)$ & \\
\hline Inflammation & $4(3)$ & \\
\hline Gliosis & $4(3)$ & \\
\hline Lymphoid infiltration & $1(1)$ & \\
\hline
\end{tabular}

Failure in diagnosis was significantly associated with male gender $(p=0.041)$ and HIV patient's lesions $(p=0.038)$.


Figure 1. An illustrative case of a 50-year-old female patient with a left occipital lesion in whom the SBB radically changed diagnosis and treatment. A: FLAIR MRI and B: T1-enhanced in axial view showing a heterogeneous cortical lesion, with medium enhancement and central hypointense areas. C: Axial enhanced-CT with the stereotactic frame prior to the surgical procedure. D: Histopathological 100x with acute inflammation over a chronic granulomatous process with focal areas of necrosis and vasculitis. Before the SBB, a neoplastic lesion was suspected, the final result was a syphilitic gumma.

\section{Complications}

We performed a post-operative CT scan for all patients looking for early complications. During our observation period, one death was documented, in a patient with a paraventricular temporal lesion with massive intraventricular hemorrhage in the post-operative period who ultimately had a diagnosis of low-grade astrocytoma. We documented three patients with small local bleedings in the biopsy area, all of whom did not require complementary surgical management, one of these cases corresponded to symptomatic hemorrhage with focal paresis of the right arm without posterior impact on clinical functionality. Symptomatic postoperative edema occurred in two patients requiring complementary management with dexamethasone $8 \mathrm{mg} \mathrm{BID}$. In three patients pneumocephalus was documented by post-operative CT scan without clinical symptoms.

\section{Discussion}

In this 53 month retrospective study, we report important data about frame-based SBB in a tertiary 
referral hospital in Mexico. We found that high-grade astrocytomas were the most frequently diagnosed lesions, with high diagnostic accuracy (94\%) and low number of complications (6\%).

As in other series, the majority of patients were men in the fourth and fifth decades of life (61\%), which correlates with the higher incidence of high grade astrocytomas in this age $\operatorname{span}^{9,10}$.

Lobar subcortial lesions were the majority $46 \%$, followed by diencephalic $19 \%$, and deep seated in $18 \%$, this is similar to that previously described in other series $^{8,11}$. Tilgner et al., ${ }^{12}$ reported that biopsies of tumors located in the parietal lobe are more accurately diagnosed than those in other locations. In our cases, the location of the lesion was not associated with a better diagnostic accuracy.

According to that previous reported regarding diagnoses, all the series agree that high-grade astrocytomas (WHO Grades III and IV) are the most biopsied lesions, followed by central nervous system lymphomas and metastases. Nevertheless, the proportion of high-grade astrocytomas in our series is greater $(40 \%)$ that the previously reported by other authors $\left(21 \%{ }^{13}\right.$, $26 \%{ }^{14}, 32 \% \%^{10,11}$, and $34 \%{ }^{15}$ ), this can be partly due by ethnic differences in our population, unknown to the best of our knowledge.

Regarding non-neoplastic lesions, we found a higher proportion of toxoplasmosis (4\%) compared to other series $\left(1 \%{ }^{16}\right)$, where the most reported findings were abscess, radionecrosis, and vascular lesions such as infarctions ${ }^{11,12,14}$. This can be explained by a large number of biopsied HIV patients in our series $(9 \%)$.

When comparing the pre-surgical radiological diagnosis with the SBB result, we found that it was reliable only in $39 \%$ of cases, with better performance in the case of vascular (100\%) and infectious lesions (47\%). This data are comparable to that previously reported by Tilgner and collaborators $(30 \%)^{12}$, but is far from those reported in the Quick-Weller series $(76 \%)^{17}$, although the latter takes into account only lesions of the brainstem, which could facilitate radiological diagnosis. Any parameter we take, supports the use of SBB, since the reliability of the radiological diagnosis is low, so relying on the latter, can result in inappropriate treatment.

With respect to postoperative complications (6\%), the occurrence of hemorrhage at the biopsied site is the most frequent complication as reported in other studies $(2-8 \%)^{8,10,11,16,18}$ and was present in $2 \%$ of our cases, being the cause of death in one patient, and only demonstrated by post-operative CT scan in two patients. Of the nine cases reported in our series as complications, two were secondary to cerebral edema corresponding to $1 \%$ of the series. Transient neurological deficit was another complication, most likely secondary to edema at the biopsied site ${ }^{10,14,19}$. In three patients intracranial air collection was evident in post the post-operative CT scan, without clinical symptoms, not requiring further treatment and without demonstrable image displacement of the stereotactic objective. We found no information regarding this complication in the literature.

In the previous reports, mortality secondary to SBB was settle from $1 \%$ to $2 \% 14,15,19$. Risk factors associated with mortality are size of the lesion to be biopsied, particularly for neoplasms; increase in neovascularization, which confers a greater possibility of edema and hemorrhage and patients with a lower degree of functionality ${ }^{16,19,20}$.

Accurate histological diagnosis is essential for the patient's appropriate and effective treatment options according to the type of brain lesion. The overall diagnostic yield of SBB in our series was $94 \%$, being among the highest in the literature. This number is comparable to that previously described by Nishihara et al. $97 \%^{18}$, Hall et al. $95 \%{ }^{14}$, and Waters et al., 95\% Success of SBB derives from surgeon's experience, which improves diagnostic performance up to $10 \%{ }^{21}$, having in the operating room an experienced neuropathologist analyzing the adequacy of the biopsied material ${ }^{7,12,15}$, the nature of biopsied lesions, being easier to determine the diagnosis in high grade tumors $^{8,12,15}$, and the number of samples obtained ${ }^{13,22}$. Furthermore, lesions $>1 \mathrm{~cm}^{7}$ represent an easier target to approach. The high diagnostic accuracy in our study is most likely related to the conjunction of these factors. When conducting an intentional search for what we consider to be a primary factor for success in diagnostic performance, which is the presence of a neuropathologist who determines the adequacy of the sample, we find that the existing evidence supports this hypothesis. Tsermoulas et al. found that the failure in diagnosis decreased from $7 \%$ to $6 \%$ when incorporating the neuropathologist for the trans-surgical review of the sample obtained ${ }^{23}$. It is the same case of Hall et al. whom reported an increase in diagnostic performance from $80 \%$ to $96 \%{ }^{14}$. On the other hand, in the studies where the biopsy was not evaluated in the surgery, diagnostic yields were reported between $83 \%{ }^{13}$ y $86 \%{ }^{10}$. 
Complementary surgical resection was performed in 20 cases (14\%); data that agrees with that previously reported in other series such as that of LaraAlmunia et al. $20 \%^{21}$ and $\mathrm{Kim}$ et al. $15 \%{ }^{15}$. In the present study, in all these 20 cases there was a diagnostic doubt of neoplastic versus infectious etiology, when neoplastic lesion was confirmed by SBB, the complementary resection was performed.

The limitation of the present study is its retrospective design, which does not allow us to evaluate the variables that could affect the overall diagnostic performance.

\section{Conclusion}

Frame-based SBB continues to be a safe, useful and inexpensive procedure, requiring but 2-3 days hospitalization, particularly for those cases where cytoreduction is not a first instance option, either due to the location of the lesion or the patient's physiological status. The diagnostic performance of SBB increases when strategies such as the intraoperative cytological evaluation by a neuropathologist are included in the study. A higher number of biopsy samples also increases diagnostic accuracy.

\section{Conflicts of interest}

The authors declare that does not exist an conflict of interest.

\section{Ethical disclosures}

Protection of human and animal subjects. The authors declare that no experiments were performed on humans or animals for this study.

Confidentiality of data. The authors declare that they have followed the protocols of their work center on the publication of patient data.

Right to privacy and informed consent. The authors have obtained the written informed consent of the patients or subjects mentioned in the article. The corresponding author is in possession of this document.

\section{References}

1. Apuzzo ML, Chandrasoma PT, Cohen D, Zee CS, Zelman V. Computed imaging stereotaxy: experience and prospective related to 500 procedures applied to brain masses. Neurosurgery. 1987;20:930-7.

2. Apuzzo ML, Chandrasoma PT, Zelman V, Giannotta SL, Weiss MH. Computed tomographic guidance stereotaxis in the management of lesions of the third ventricular region. Neurosurgery. 1984;15:502-8.

3. Apuzzo ML, Sabshin JK. Computed tomographic guidance stereotaxis in the management of intracranial mass lesions. Neurosurgery. 1983;12:277-85.

4. Rajshekhar V. Current status of stereotactic biopsy. Stereotact Funct Neurosurg. 2001;76:137-9.

5. Dammers R, Haitsma IK, Schouten JW, Kros JM, Avezaat CJ, Vincent AJ. Safety and efficacy of frameless and frame-based intracranial biopsy techniques. Acta Neurochir. 2008;150:23-9.

6. Aker FV, Hakan T, Karadereler S, Erkan M. Accuracy and diagnostic yield of stereotactic biopsy in the diagnosis of brain masses: comparison of results of biopsy and resected surgical specimens. Neuropathology. 2005;25:207-13.

7. Waters JD, Gonda DD, Reddy H, Kasper EM, Warnke PC, Chen CC. Diagnostic yield of stereotactic needle-biopsies of sub-cubic centimeter intracranial lesions. Surg Neurol Int. 2013;4:110677.

8. Grunert P, Ungersböck K, Bohl J, Kitz K, Hopf N. Results of 200 intracranial stereotactic biopsies. Neurosurg Rev. 1994;17:59-66.

9. Bishokarma S, Shrestha P, Koirala S, Raut M, Gongal DN. Venture in 101 cranial punctures: a comparative study between frame-based versus frameless biopsy of 101 intracranial space occupying lesion. Asian J Neurosurg. 2019;14:175-80.

10. Yu X, Liu Z, Tian Z, Li S, Huang H, Xiu B, et al. Stereotactic biopsy for intracranial space-occupying lesions: clinical analysis of 550 cases. Stereotact Funct Neurosurg. 2000;75:103-8.

11. Field M, Witham TF, Flickinger JC, Kondziolka D, Lunsford LD. Comprehensive assessment of hemorrhage risks and outcomes after stereotactic brain biopsy. J Neurosurg. 2001;94:545-51.

12. Tilgner J, Herr M, Ostertag C, Volk B. Validation of intraoperative diagnoses using smear preparations from stereotactic brain biopsies: intraoperative versus final diagnosis-influence of clinical factors. Neurosurgery. 2005:56:257-63.

13. Jain D, Sharma MC, Sarkar C, Deb P, Gupta D, Mahapatra AK. Correlation of diagnostic yield of stereotactic brain biopsy with number of biopsy bits and site of the lesion. Brain Tumor Pathol. 2006;23:71-5.

14. Hall WA. The safety and efficacy of stereotactic biopsy for intracranial lesions. Cancer. 1998;82:1749-55.

15. Kim JE, Kim DG, Paek SH, Jung HW, Lobato RD, Ostertag C. Stereotactic biopsy for intracranial lesions: reliability and its impact on the planning of treatment. Acta Neurochir (Wien). 2003;145:547-55.

16. Kongkham PN, Knifed E, Tomber MS, Bernstein M. Complications in 622 cases of frame-based stereotactic biopsy, a decreasing procedure. Can J Neurol Sci. 2008;35:79-84.

17. Quick-Weller J, Lescher S, Bruder M, Dine N, Behmanesh B, Seifert V, et al. Stereotatic biopsy of brainstem lesions: 21 years experiences of a single center. J Neurooncol. 2016;129:243-50.

18. Nishihara M, Sasayama T, Kudo H, Kohmura E. Morbidity of stereotactic biopsy for intracranial lesions. Kobe J Med Sci. 2010;56:148-53.

19. Teixeira MJ, Fonoff ET, Mandel M, Alves HL, Rosemberg S. Stereotactic biopsies of brain lesions. Arq Neuropsiquiatr. 2009;67:74-7.

20. Lopez-Flores G, Guerra-Figueredo E, Fernandez-Melo R, Bouza-Molina W, Estupiñan-Diaz B, Jordan-Gonzalez JA. Biopsia estereotáxica de las lesiones intracraneales, Revisión del tema. Rev Mex Neuroci. 2001;2:14-23.

21. Lara-Almunia M, Hernandez-Vicente J. Frame-based stereotactic biopsy: description and association of anatomical, radiologic, and surgical variables with diagnostic yield in a series of 407 cases. J Neurol Surgery Part A Cent Eur Neurosurg. 2019;80:149-61.

22. Dammers R, Schouten JW, Haitsma IK, Vincent AJ, Kros JM, Dirven CM. Towards improving the safety and diagnostic yield of stereotactic biopsy in a single centre. Acta Neurochir. 2010;152:1915-21.

23. Tsermoulas G, Mukerji N, Borah AJ, Mitchell P, Ross N. Factors affecting diagnostic yield in needle biopsy for brain lesions. $\mathrm{Br} \mathrm{J}$ Neurosurg. 2013;27:207-11. 